$\begin{array}{lll}\sum_{\text {Jorrit Gerritsen }} & \text { Beatrix Children's Hospital } & \text { jorrit@gmail.com } \\ \text { University Medical Center } \\ \text { Groningen } \\ \text { University of Groningen } \\ \text { Groningen } \\ \text { The Netherlands }\end{array}$

BOOK REVIEW

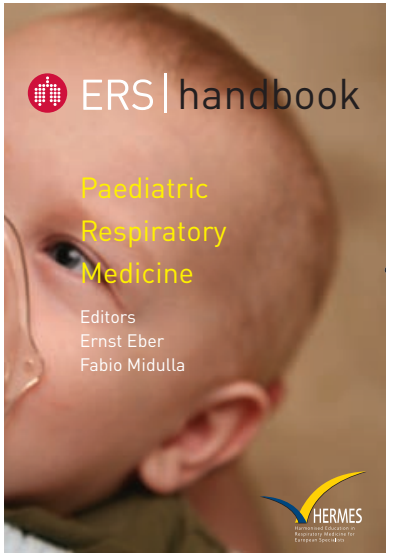

\title{
ERS Handbook of Paediatric Respiratory Medicine
}

\author{
Editors: Ernst Eber, Fabio Midulla \\ Publisher: ERS; 719 pages; \\ ISBN: 9781849840385
}

\begin{abstract}
The ERS Handbook of Paediatric Respiratory Medicine is priced at $€ 55$ for ERS members $€ 70$ for non-members from the ERS

Bookshop: www.ersbookshop.com
\end{abstract}

edited by Ernst Eber and Fabio Midulla, was launched in 2013 at the ERS Annual Congress in Barcelona.

It is very good to see that so many clinicians involved in paediatric pulmonary diseases contributed to this first edition of the handbook and it reflects the hard work of and the scientific potential in the paediatric assembly.

This handbook covers all aspects of paediatric respiratory medicine and the information is very well presented. This holistic approach is the basis for this handbook as a guideline to the preparation for the HERMES exam. However, in fact it is applicable not only for this purpose but is also excellent for the use in daily practice. In several chapters, clear guidelines are given, which can be implemented, while other chapters give more theoretical background.

Like in all handbooks, the weakness is the clarity of the presentation of the figures and radiographs, but this is compensated by the availability of this information as a PDF file, in which the figures and radiographs can be enlarged and studied in more detail.

With so many contributors, some overlap is unavoidable, especially when authors are involved in more than one chapter and, sometimes, they focus too much on their own the need for a corresponding book; and the ERS Handbook on Paediatric Respiratory Medicine, 
research and fail to give the reader the necessary broad view of their topic.

The CME questions for each chapter are very well drafted and give an indication of the questions which can be expected in the Paediatric HERMES exam.

Overall, the editors have done an excellent job. The book is practical and provides the reader with up-to-date information on all aspects of respiratory medicine in children.

Although handbooks with more extensive and more detailed information remain necessary, this book should be at hand for every clinician working in the field of respiratory medicine in children and is an excellent book for reference and quick consultation.

\section{References}

1. Zach, MS. Paediatric respiratory training in Europe: syllabus and centres. Eur Respir J 2002; 20: 1587-1593.

2. Palange P, Simonds A, eds. ERS Handbook of Respiratory Medicine. Sheffield, ERS, 2010. 